\title{
Application of the Principles of the Marine Ecosystems' Adaptive Modeling to the Hydrochemical Observations in the Sevastopol Bay
}

\author{
I. E. Timchenko*, E. M. Igumnova, S. V. Svishchev \\ Marine Hydrophysical Institute, Russian Academy of Sciences, Sevastopol, Russian Federation \\ *e-mail: timchenko.syst.analysis@mhi-ras.ru
}

Introduction. Scenarios of development of the processes in the complex marine ecosystems are forecasted by the models developed for marine ecosystems. At that the method for formalizing the scheme of the cause-effect relations (impacts) is required. In other words, it is necessary to construct the equation system for the model variables connecting the functions representing the modeled processes.

Data and Methods. Proposed are the methods for modeling the processes in the marine ecosystems based on the system principles of the adaptive balance of causes and informational unity of the processes' models and the corresponding observational data.

Analysis of Results. It is shown that application of these principles permits to construct the adaptive models with negative feedbacks of the $1^{\text {st }}$ and the $2^{\text {nd }}$ orders between the model variables and the speed of their variation. These models provide automatic fitting of the model variables to each other and to the external effects; at the same time they preserve the matter balances in the substance transformation reactions in the marine environment. The simulation results reveal that the $2^{\text {nd }}$ order adaptive models are more sensitive to the external effects influencing the ecosystem and adapt to them quicker. Application of the adaptive modeling principles is illustrated by the data of hydrochemical observations in the Sevastopol Bay. Two methods of reconstructing dynamics of the nitrite concentration are comparatively analyzed using the time series of the ammonium and nitrate observations.

Discussion and Conclusions. It is shown that the dynamic-stochastic equation provides much higher accuracy of reconstruction of the unobserved process of the nitrite concentration as compared to the method of the normalized relations of the mean values. Besides, the reconstruction accuracy increases with growth of length of the observation time series applied at constructing their covariance matrix.

Keywords: adaptive modeling, adaptive balance of causes, marine ecosystem, reconstruction of the unobserved processes, influence coefficients, covariance matrix, dynamic-stochastic equation, nitrification, Sevastopol Bay.

Acknowledgements: the investigations are carried out within the framework of the state task on the theme No. 0827-214-0010 "Complex interdisciplinary investigations of the oceanic processes which condition functioning and evolution of the Black and Azov seas' ecosystems based on the modern methods of marine environment state control and the hydraulic technologies". The model is developed and the computing experiments are performed within the framework of the scientific project of the Russian Foundation for Basic Research and the Sevastopol Administration No. 18-47920001 "Study of the principles for constructing adaptive models of the ecological-economic systems and digital informational technologies for managing the scenarios of sustainable development of natural and economical complexes in the Seavastopol region".

For citation: Timchenko, I.E., Igumnova, E.M. and Svishchev, S.V., 2019. Application of the Principles of the Marine Ecosystems' Adaptive Modeling to the Hydrochemical Observations in the $\begin{array}{llll}\text { Sevastopol Bay. Physical Oceanography, [e-journal] 26(1), pp. 63-76. } & \end{array}$ doi:10.22449/1573-160X-2019-1-63-76

DOI: $10.22449 / 1573-160 \mathrm{X}-2019-1-63-76$

(C) 2019, I. E. Timchenko, E. M. Igumnova, S. V. Svishchev

(C) 2019, Physical Oceanography 
Introduction. The creation of a marine ecosystem dynamic model is preceded by its verbal description, which, in accordance with the systems analysis principles [1-5], combines the most important processes in the marine environment in terms of the modeling purpose. A graphical depiction of a verbal model (a conceptual model) contains a diagram of cause-effect relationships representing the directions and signs of the effects of some processes on others. Having such a scheme of effects, it is necessary to construct a system of equations linking the functions of the model variables that represent the modeled processes.

The general principle of formalization of the conceptual models, discovered by I. Newton, states that the dynamic equations of processes should link the model variables with the change rates of these variables, taking into account internal and external effects*. At the same time, the effects are considered as the reasons causing deviations of a stable system of interrelated processes from its stationary equilibrium state, and negative feedback of a variable with its variation rate is considered as a factor of stability. Similar methods of formalization are used in the theory of complex adaptive control systems [6-14]. The idea of I. Newton is implemented through the use of negative feedbacks in the dynamic equations of control objects, which automatically maintain the balances of intrasystem and external effects in the complex systems.

Similar approach is applied in the adaptive balance of causes method $(A B C$ method), proposed in $[4,12]$ for the modeling of marine ecosystems and the land sea ecological-economic systems. In this method, along with the well-known principles of system analysis (system integrity, completeness of intrasystem connections between its objects, etc.), new principles are used: adaptive balance of causes and informational unity of the dynamic model of processes and the data of observations over these processes. The first principle serves as the basis for the creation of a new class of adaptive models designed to predict the development scenarios for processes in complex systems. The second one provides the assimilation of observational data in the adaptive predictive models of the systems and is applied for creation of digital information technologies to manage the predicted development scenarios.

The sustainability of ecosystems observed in the nature is explained by their inherent property of adaptation to the changing conditions of the existence of living organisms [13-15]. This property is applied in the method of constructing the adaptive models of marine ecosystems considered in this work. The main problem of constructing the models of marine ecosystems is to find the coefficients of equations that formalize the cause-effect relationships between the modeled processes. Additional information required for this is usually contained in the wellknown regularities of the transformation of chemical substances in the marine environment and the interaction of living objects in it [15]. However, the parameterization of cause-effect relationships used in this approach contains a large number of constants, the determination of which makes the modeling difficult.

*Newton, I., 1999. The Principia: Mathematical Principles of Natural Philosophy. Berkeley: University of California Press, 1025 p. 
The prospects for eliminating such difficulties are associated with the increasing volume of instrumental observations carried out at the sea. Regular surveys of chemical-biological parameter fields performed within the framework of programs for marine coastal environment monitoring (for example, see [11], as well as information about the grant* and report ${ }^{* *}$ ) allow us to use time series of observations to estimate the coefficients of dynamic ecosystem models. In this work, the algorithms for formalizing the relationships between the processes in the marine ecosystem adaptive model based on observational data accumulated as a result of multi-annual surveys of hydrochemical and hydrobiological fields are proposed. In particular, the purpose of this work was to construct an adaptive model dynamic equation of the marine environment nitrification from the time series of observations carried out in the Sevastopol Bay waters.

Adaptive models of cause-effect relationships in the marine ecosystems. These models are based on the application of the system principle of adaptive balance of causes $[4,12]$. The principle postulates that the ecosystem is in an equilibrium (stationary) state when external effects applied to it are absent. In this state, the concentrations of substances $u_{i}$ retain average values $C_{i}$. External effects $A_{i}$ lead to the deviations of concentrations from their equilibrium values, and the ecosystem continuously adapts the concentrations of substances in such a way that the balance of effects conservation law is satisfied. The essence of this law is to conserve the material balances of substance transformation in the marine ecosystem: under effect of internal and external influences, the ecosystem variables take on such values that ensure the satisfaction of the condition

$$
u_{i}-C_{i}=\sum_{j=1, j \neq i}^{n} a_{i j}\left(u_{j}-C_{j}\right)+A_{i} .
$$

In this expression $a_{i j}$ are the coefficients of the substance concentration deviation effects $u_{j}$ (reaction resources) from their mean values $C_{j}$, forming a deviation (of the reaction product) from its mean value $C_{i}$. The number $n$ indicates the number of modeled processes, and the symbol $A_{i}$ indicates the external effects applied to the ecosystem.

* INTAS 2003-51-6196. Energetics of Heterotrophic-Photoautotrophic Microbial Interaction: Verification of HP Index and Functional Role of the Community Size Structure. Available at: https://cordis.europa.eu/project/rcn/71808_en.html [Accessed: 20 December 2018].

** Konovalov, S.K., Kondrat'ev, S.I., Moiseenko, O.G., Romanov, A.S., Ovsyanyy, E.I., Vnukov, Yu.L., Orekhova, N.A., Chumakova, N.I., Khoruzhiy, D.S., Kotel'yanets, E.A. and Svishchev, S.V., 2009. Otchet o Gidrokhimicheskoy S'emke Sevastopol'skoy Bukhty i Reki Chernaya 18.09.2009 g. - 22.09.2009 g. [Report on the Hydrochemical Survey of the Sevastopol Bay and the Chernaya River 18.09.2009 -22.09.2009]. Sevastopol: MHI, 32 p. (in Russian). 
Using the principle of constructing the equations of dynamic processes, we represent the right parts of a formalized ecosystem model in the form of functionals of influences $F_{i}\left(u_{i}, u_{j}, A_{i}\right)$ :

$$
\frac{d u_{i}}{d t}=F_{i}\left(u_{i}, u_{j}, A_{i}\right)
$$

The preservation of the effect balances will be achieved if the following restrictions will be imposed on the system of equations (2):

$$
\begin{gathered}
F_{i}\left(u_{i}, u_{j}, A_{i}\right)=C_{i} ; \\
\frac{d u_{i}}{d t}=r_{i}\left[C_{i}-F_{i}\left(u_{i}, u_{j}, A_{i}\right)\right],
\end{gathered}
$$

where $r_{i}$ is the specific rate of function $u_{i}$ variation. As the solutions of the system of equations (3) are achieved at such $u_{i}$ values when all the derivatives of the system simultaneously vanish, the functionals of effects must be expressed from the conditions for the preservation of material balances (1):

$$
F_{i}\left(u_{i}, u_{j}, A_{i}\right)=C_{i}=u_{i}-\sum_{j=1, j \neq i}^{n} a_{i j}\left(u_{j}-C_{j}\right)-A_{i} .
$$

Substituting expression (4) into the formula (3), we obtain the system of equations of the adaptive balance of causes method with the negative first-order feedback relations with respect to $u_{i}$ variables

$$
\frac{d u_{i}}{d t}=r_{i}\left\{C_{i}-\left[u_{i}-\sum_{j=1, j \neq i}^{n} a_{i j}\left(u_{j}-C_{j}\right)-A_{i}\right]\right\} .
$$

We represent the system of equations (5) in finite differences:

$$
u_{i}^{k+1}=u_{i}^{k}+\Delta t r_{i} C_{i}-\Delta t r_{i}\left[u_{i}^{k}-\sum_{j=1, j \neq i}^{n} a_{i j}\left(u_{j}^{k}-C_{j}\right)-A_{i}^{k}\right] .
$$

For the simplification, we accept the condition $\Delta t r_{i} C_{i}=1$ which can always be satisfied with the selection of the integration step over the time $\Delta t$. Then we obtain

$$
u_{i}^{k+1}=u_{i}^{k}+1-\frac{1}{C_{i}}\left[u_{i}^{k}-\sum_{j=1, j \neq i}^{n} a_{i j}\left(u_{j}^{k}-C_{j}\right)-A_{i}^{k}\right] .
$$

The equations with the first-order negative feedbacks are widely used in the implications of the theory of complex adaptive systems in natural science and technology [7, 9-12]. In particular, such equations are applied in the well-known method of system dynamics developed by J. Forrester [16]. At the same time, there 
are other ways of representing the functional $F_{i}\left(u_{i}, u_{j}, A_{i}\right)$ in system (2) that satisfy the conditions for preserving the balances of effects.

In $[4,12]$ a different overall structure of the equations (3) was proposed:

$$
\frac{d u_{i}}{d t}=r_{i}\left[u_{i} F_{i}^{-}-u_{i} F_{i}^{+}\right] \text {, }
$$

in which $F_{i}^{+}$is monotonously increasing and $F_{i}^{-}$is monotonously decreasing basic functionals of effects (4). In this case, $F_{i}^{-}$functionals restrain the growth of $u_{i}$ variables, controlling the positive effects of the sources, while the functionals $F_{i}^{+}$ restrain the negative effects of the sinks, tending the variables $u_{i}$ to zero. If we connect the functionals $F_{i}^{-}$and $F_{i}^{+}$among themselves by an additional condition

$$
F_{i}^{-}+F_{i}^{+}=2 C_{i},
$$

then the management of sources and sinks becomes consistent and the ecosystem model acquires the adaptive property of automatic preservation of the balances of effects.

For example, let the variable $u_{i}$ in an ecosystem equation be affected by $m$ of positive and $n-m$ of negative effects. Then the functionals $F_{i}^{+}$take the form

$$
F_{i}^{+}=u_{i}-\sum_{k=1, k \neq i}^{m} a_{i k}\left(u_{k}-C_{k}\right)+\sum_{l=1, l \neq i}^{n-m} a_{i l}\left(u_{l}-C_{l}\right)-A_{i} .
$$

Substituting this expression into the system of equations (8) and using the relations (6) to determine the functionals $F_{i}^{-}$, we obtain the system of equations of an adaptive ecosystem model with the $2^{\text {nd }}$ order negative feedbacks

$$
\frac{d u_{i}}{d t}=2 r_{i} u_{i}\left\{C_{i}-\left[u_{i}-\sum_{k=1, k \neq i}^{m} a_{i k}\left(u_{k}-C_{k}\right)+\sum_{l=1, l \neq i}^{n-m} a_{i l}\left(u_{l}-C_{l}\right)-A_{i}\right]\right\}, i, j=1,2, \ldots, n \text {. }
$$

It can be easily seen that the second order negative feedback in the system of equations (7) provides the squares of $u_{i}$ variables that are present in the right sides of all equations and have the minus signs. The finite-difference representation of this system of equations at an additional condition $2 \Delta t r_{i} C_{i}=1$ takes the form

$$
u_{i}^{k+1}=2 u_{i}^{k}\left\{1-\frac{1}{2 C_{i}}\left[u_{i}^{k}-\sum_{j=1, j \neq i}^{n} a_{i j}\left(u_{j}^{k}-C_{j}\right)-A_{i}^{k}\right]\right\} \text {. }
$$

Examples of mutual adaptation of two interrelated processes. Using simple examples, we compare the adaptation properties of variables to intrasystem and external effects, which have the models of the first (5) and second (7) orders. We consider an ecosystem consisting of two interrelated processes that have the opposite (by signs) effects on each other. We assume that the ecosystem is under PHYSICAL OCEANOGRAPHY VOL. 26 ISS. 1 (2019) 
external effect $A_{2}$ applied to the second process. An adaptive ecosystem model is represented by two systems of equations:

- with negative first-order feedbacks in $v_{1}$ and $v_{2}$ variables:

$$
\begin{aligned}
& \frac{d v_{1}}{d t}=r_{1}\left\{C_{1}-\left[v_{1}-a_{12}\left(v_{2}-C_{2}\right)\right]\right\}, \\
& \frac{d v_{2}}{d t}=r_{2}\left\{C_{2}-\left[v_{2}+a_{21}\left(v_{1}-C_{1}\right)-A_{2}\right]\right\} ;
\end{aligned}
$$

- with negative second-order feedbacks in $u_{1}$ and $u_{2}$ variables:

$$
\begin{aligned}
& \frac{d u_{1}}{d t}=2 r_{1} u_{1}\left\{C_{1}-\left[u_{1}-a_{12}\left(u_{2}-C_{2}\right)\right]\right\}, \\
& \frac{d u_{2}}{d t}=2 r_{2} u_{2}\left\{C_{2}-\left[u_{2}+a_{21}\left(u_{1}-C_{1}\right)-A_{2}\right]\right\} .
\end{aligned}
$$

We set the following stationary state of the ecosystem: $C_{1}=10, C_{2}=15$.

As the coefficients of effects we select $a_{12}=0.33, a_{21}=0.75$ values.

In the first experiment the establishment of the ecosystem stationary state under random initial conditions: $v_{1}=v_{2}=u_{1}=u_{2}=1$ and $A_{2}=0$ (Fig. 1,a) was studied. In the second experiment, external effect in the form of a source function $A_{2}=10 \sin (0.8 t) \exp (-0.1 t)$ was included in each model (Fig. 1, b).

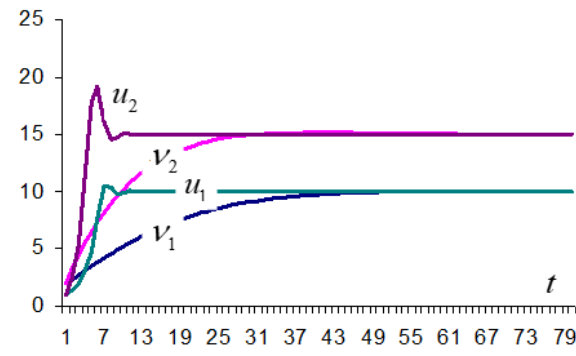

a

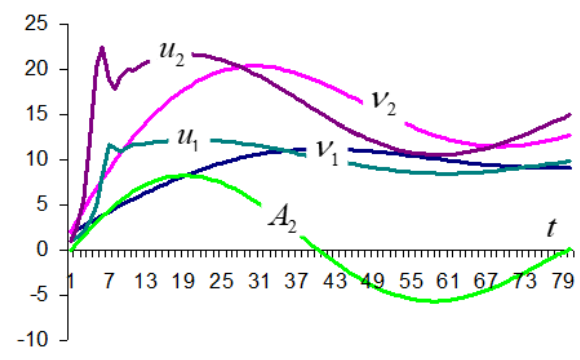

$b$

F i g. 1. Scenarios of the processes in the ecosystem adaptive models with negative feedbacks of the $1^{\text {st }}$ and the $2^{\text {nd }}$ orders

Comparison of adaptation scenarios of the $1^{\text {st }}$ and $2^{\text {nd }}$ order models leads to the conclusion about certain advantages of the $2^{\text {nd }}$ order model. First of all, the scenarios of $u_{1}$ and $u_{2}$ processes in the $2^{\text {nd }}$ order model come to a stationary state more quickly (Fig. 1, a). These scenarios are much more sensitive to external effects, which provides higher controllability of the $2^{\text {nd }}$ order models (Fig. 1, $b$ ). As a result, a delay time of scenarios with respect to external effect in the $2^{\text {nd }}$ order model is noticeably shorter than in the one of the $1^{\text {st }}$ order (Fig. 1, b). On the basis of these findings, it is advisable to use adaptive balance of causes method with second-order equations (7) - (8) when modeling cause-effect relationships in marine ecosystems. 
Estimation of effect coefficients in adaptive ecosystem models. Different approaches to the analysis of observations over the processes in ecosystems are known. The selection of approaches depends on the volume and quality of observational data available to the researcher. Probability and expert methods are proposed for estimating the effect coefficients $a_{i j}$ from observational data in $[3,4$, 8, 17]. In this study, we use the estimates based on the known statistical characteristics of the modeled processes: their mean values $C_{i}$ and the covariance relationships between them.

We consider the case when only the mean values of the modeled processes are known in advance. We reduce the resource functions $u_{j}$, included into the balance relations (2), to the intervals of ecosystem product variability $\left(0 \leq u_{i} \leq 2 C_{i}\right)$. In order to do this, we express the ecosystem model variables in the balance relations (1) in the units of the mean values of variables. Then we obtain

$$
u_{i}=C_{i}+\sum_{j=1, j \neq i}^{n} a_{i j}^{\prime} \frac{C_{i}}{C_{j}}\left(u_{j}-C_{j}\right)+A_{i}^{\prime},
$$

where $a_{i j}^{\prime}$ are dimensionless multipliers that need to be determined.

Carrying out the similar transformation brings the system of equations (7) to the following form:

$$
\begin{gathered}
\frac{d u_{i}}{d t}=2 r_{i} u_{i}\left\{C_{i}-\left[u_{i}-\sum_{k=1, k \neq i}^{m} a_{i k}^{\prime} \frac{C_{i}}{C_{k}}\left(u_{k}-C_{k}\right)+\sum_{l=1, l \neq i}^{n-m} a_{i l}^{\prime} \frac{C_{i}}{C_{l}}\left(u_{l}-C_{l}\right)-A_{i}^{\prime}\right]\right\}, \\
i, j=1,2, \ldots, n .
\end{gathered}
$$

As the effects of resources $u_{j}$ in relations (9) is proportional to the values of deviations $u_{j}^{\prime}=\left(u_{j}-C_{j}\right)$ and the degree of these effects is determined by the values of relations of mean values $u_{j}^{\prime}=\left(u_{j}-C_{j}\right)$, we can take the factors $a_{i k}^{\prime}$ and $a_{i l}^{\prime}$ as equal. This assumption means that they equally translate the effects of resources on ecosystem products. Then, from the considerations of solution stability of the system of equations (9) [11, 12], the sums of positive and negative effects should be normalized to 0.5 :

$\frac{d u_{i}}{d t}=2 r_{i} u_{i}\left\{C_{i}-\left[u_{i}-\frac{C_{i}}{2 m} \sum_{k=1, k \neq i}^{m} C_{k}^{-1}\left(u_{k}-C_{k}\right)+\frac{C_{i}}{2(n-m)} \sum_{l=1, l \neq i}^{n-m} C_{l}^{-1}\left(u_{l}-C_{l}\right)-A_{i}\right]\right\}$.

Construction of an adaptive model equation with normalized effect coefficients according to the data of hydrochemical observations performed in the Sevastopol Bay. In order to test the proposed method for estimating the effect coefficients, we used observational data for hydrochemical processes obtained in the Sevastopol Bay waters from May 1998 to September 2016. During this period 81 hydrologic-hydrochemical surveys of inorganic dissolved nitrogen concentrations were performed. According to the results of these surveys, time PHYSICAL OCEANOGRAPHY VOL. 26 ISS. 1 (2019) 
series of ammonium $\mathrm{NH}_{4}$, nitrite $\mathrm{NO}_{2}$ and nitrate $\mathrm{NO}_{3}$ observations were formed. As the measurements during this 18-year period were carried out irregularly, the measurement results were combined into total arrays and subjected to moving averaging with 30 days interval in order to compile the most representative sample of data. Thus, the graphs of multiannual average monthly variability of hydrochemical parameter concentrations in the ecosystem of the Sevastopol Bay were obtained. The revealed cause-effect relationships between nitrogen forms (Fig. 2) are consistent with those presented in [18].

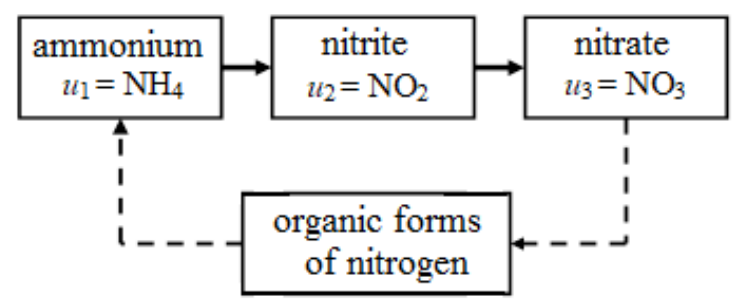

F i g. 2. The first and the second stages of the nitrification process in the nitrogen cycle structure in the Sevastopol Bay

We construct an adaptive equation for nitrite concentration $u_{2}$ at some point of the bay, taking into account the fact that the ammonium concentration $u_{1}$ is spent on its increase, and the nitrite concentration $u_{2}$, in turn, is spent on increasing the concentration of nitrates $u_{3}$ (see Fig. 2). We assume that only time series of observations of ammonium $\mathrm{NH}_{4}$ and nitrates $\mathrm{NO}_{3}$, as well as the average values of all processes, are known. The problem is to reconstruct the series of $\mathrm{NO}_{2}$ observations using equation (10) with normalized effect coefficients a special case of which was considered in [18]. Assuming in this equation $n=2, m=1$, we obtain

$$
\frac{d u_{2}}{d t}=2 r_{2} u_{2}\left\{C_{2}-\left[u_{2}-\frac{C_{2}}{2} C_{1}^{-1}\left(u_{1}-C_{1}\right)+\frac{C_{2}}{2} C_{3}^{-1}\left(u_{3}-C_{3}\right)\right]\right\},
$$

or in finite differences with regard to equations (8)

$$
u_{2}^{k+1}=2 u_{2}^{k}\left\{1-\frac{1}{2 C_{2}}\left[u_{2}^{k}-\frac{C_{2}}{2} C_{1}^{-1}\left(u_{1}^{k}-C_{1}\right)+\frac{C_{2}}{2} C_{3}^{-1}\left(u_{3}^{k}-C_{3}\right)\right]\right\} .
$$

The graphs of mean multiannual monthly average variability of $\mathrm{NH}_{4}, \mathrm{NO}_{2}$ and $\mathrm{NO}_{3}$ concentrations are shown in Fig. 3, $a-c$. The results of calculations at $C_{1}=5.60 \mathrm{mg} \mathrm{N} / \mathrm{m}^{3}, C_{2}=2.03 \mathrm{mg} \mathrm{N} / \mathrm{m}^{3}$ and $C_{3}=42.35 \mathrm{mg} \mathrm{N} / \mathrm{m}^{3}$ are represented in Fig. 3, $d$. 

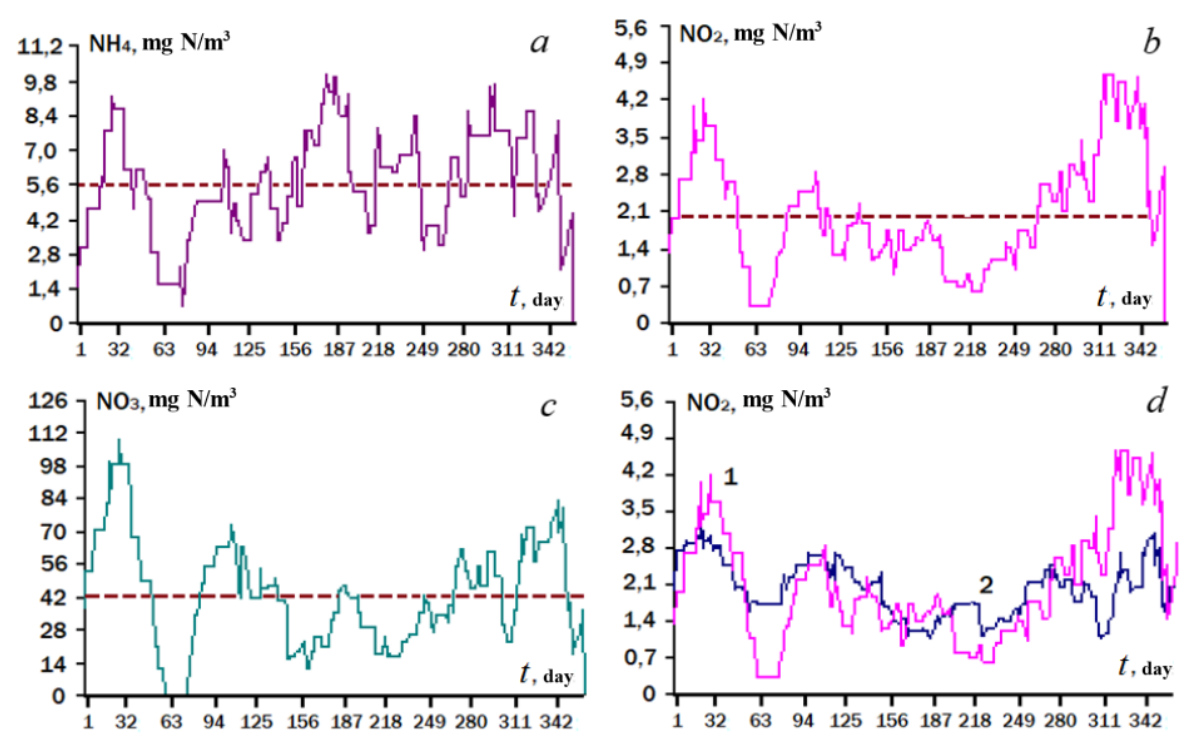

F i g. 3. Intra-annual variability of hydrochemical parameters $\left(\mathrm{mg} \mathrm{N} / \mathrm{m}^{3}\right)$ in the Sevastopol Bay: $\mathrm{NH}_{4}$ $(a), \mathrm{NO}_{2}(b), \mathrm{NO}_{3}(c)$; comparison of the observed (pink curve) and the modeled (blue curve) $\mathrm{NO}_{2}$ concentrations $(d)$

As follows from Fig. 3, $d$, reconstructed $\mathrm{NO}_{2}$ concentration scenario (blue curve) is basically correct when monitoring the trends of real scenario variation (pink curve). However, the deviations of the reconstructed scenario from mean value $C_{2}=2.03 \mathrm{mg} \mathrm{N} / \mathrm{m}^{3}$ are noticeably smaller than those of the real one. Therefore, the ratio of reconstruction error variance to the variance of real scenario was 1.94 , which corresponds to the ratio of root-mean-square values equal to 1.38 . It should be pointed out that for reconstructing the scenario using this method we used the minimal information about $\mathrm{NO}_{2}$ process (only its mean value).

The use of statistical relationships between the modeled processes for constructing a dynamic-stochastic equation of the $2^{\text {nd }}$ order adaptive model. Now we assume that in addition to the average values of the processes, the coefficients of statistical relationships between all processes are also known. The equations in which statistical relationships between observational data are used to refine predictive model estimates will be called dynamical-stochastic ones [8]. We set an objective: to express the values of dimensionless factors $a_{i k}^{\prime}$ and $a_{i l}^{\prime}$ in the system of equations (9) through the known statistical relations of processes, using their covariance matrix $R_{i j}=E\left\{u_{i} u_{j}\right\}$. We denote the processes deviations from their average values as $u_{i}^{\prime}=u_{i}-C_{i}$. In this case, the balance relations underlying the adaptive model (9) can be represented in the following form:

$$
u^{\prime}=\sum_{k=1, k \neq i}^{m} a_{i k}^{\prime} \frac{C_{i}}{C_{k}} u_{k}^{\prime}-\sum_{l=1, l \neq i}^{n-m} a_{i l}^{\prime} \frac{C_{i}}{C_{l}} u_{l}^{\prime}+A_{i}^{\prime},
$$


where $A_{i}^{\prime}$ are the deviations of external effects by the processes $u_{i}$ from their mean values. We assume that external effects do not correlate with internal processes in the ecosystem. This assumption follows from the system analysis principles [1-3]: internal processes in the system cannot affect external processes in the environment, because the processes in the environment will otherwise be elements of the system itself and then they should be included in its structure.

Multiplying the right side of equation (11) alternately by $u_{k}^{\prime}$ and $u_{l}^{\prime}$, performing the averaging of the obtained expressions and using the notation for the elements of the covariance matrix $R_{i j}$, we obtain the following system of algebraic equations for the factors $a_{i k}^{\prime}$ and $a_{i l}^{\prime}$ :

$$
\begin{aligned}
& R_{i k}=\sum_{k=1, k \neq i}^{m} a_{i k}^{\prime} C_{i} C_{k}^{-1} R_{k k}-\sum_{l=1, l \neq i}^{n-m} a_{i l}^{\prime} C_{i} C_{l}^{-1} R_{l k}, \\
& R_{i l}=\sum_{k=1, k \neq i}^{m} a_{i k}^{\prime} C_{i} C_{k}^{-1} R_{k l}-\sum_{l=1, l \neq i}^{n-m} a_{i l}^{\prime} C_{i} C_{l}^{-1} R_{l l} .
\end{aligned}
$$

Solution of this system of equations completes the construction of dynamicstochastic model (9), (12) for describing cause-effect relationships in marine ecosystem. In order to make the solutions of equations (9) satisfy the determined intervals of variable variations $\left(0 \leq u_{i} \leq 2 C_{i}\right)$, the system of these equations must be supplemented with logical conditions

$$
u_{i}=\left\{\begin{array}{l}
0, i f\left[u_{i}<0\right] \\
u_{i} \\
2 C_{i}, i f\left[u_{i}>2 C_{i}\right]
\end{array} .\right.
$$

Application of dynamic-stochastic equation of the $2^{\text {nd }}$ order adaptive model to the data of hydrochemical observations in the Sevastopol Bay. We apply the system of dynamic-stochastic equations (9), (12), (13) to the aboveconsidered hydrochemical observational data from the Sevastopol Bay. In order to reconstruct the scenario of the process $u_{2}$, not only the values of the processes $u_{1}^{\prime}$ and $u_{3}^{\prime}$, but also the elements of the covariance matrix $R_{i j}, i, j=1,2,3$, are required. This makes it possible to reconstruct scenarios of process $u_{2}$ from observational data of $u_{1}$ and $u_{3}$ processes using current or previous values of the covariance matrix.

We construct the balance ratio linking the reactions of the substance interactions (Fig. 2) with no regard to external effects:

$$
u_{2}^{\prime}=a_{21} u_{1}^{\prime}-a_{23} u_{3}^{\prime} .
$$

We reduce the variables $u_{1}$ and $u_{3}$ to the variance interval of $u_{2}$ variable. For this, all the variables will be expresses in the units of average values, the same way as relation (15) was derived: 


$$
u_{2}^{\prime}=a_{21}^{\prime} \frac{C_{2}}{C_{1}} u_{1}^{\prime}-a_{23}^{\prime} \frac{C_{2}}{C_{3}} u_{3}^{\prime} .
$$

Multiplying the expression (14) alternately by $u_{1}^{\prime}$ and $u_{3}^{\prime}$, performing averaging of the obtained expressions and taking into account the notations of the covariance matrix $R_{i j}$ elements, we obtain the system of equations for finding the dimensionless factors $a_{21}^{\prime}$ and $a_{23}^{\prime}$

$$
\begin{array}{lll}
R_{21}=a_{21}^{\prime} \frac{C_{2}}{C_{1}} R_{11}-a_{23}^{\prime} \frac{C_{2}}{C_{3}} R_{31}, & a_{21}^{\prime}=\frac{C_{1}}{C_{2}} \frac{\left(R_{21} R_{33}-R_{23} R_{31}\right)}{\left(R_{11} R_{33}-R_{13} R_{31}\right)}, \\
R_{23}=a_{21}^{\prime} \frac{C_{2}}{C_{1}} R_{13}-a_{23}^{\prime} \frac{C_{2}}{C_{3}} R_{33}, & a_{23}^{\prime}=\frac{C_{3}}{C_{2}} \frac{\left(R_{13} R_{21}-R_{11} R_{23}\right)}{\left(R_{11} R_{33}-R_{13} R_{31}\right)} .
\end{array}
$$

Now, using the balance ration for $u_{2}$ variable

$$
u_{2}^{\prime}=C_{2}+a_{21}^{\prime} \frac{C_{2}}{C_{1}} u_{1}^{\prime}-a_{23}^{\prime} \frac{C_{2}}{C_{3}} u_{3}^{\prime}
$$

and system of equations of the model (9), we obtain the desired dynamic-stochastic equation of the adaptive model of $u_{2}$ process

$$
\frac{d u_{2}}{d t}=2 r_{2} u_{2}\left\{C_{2}-\left[u_{2}-\frac{\left(R_{21} R_{33}-R_{23} R_{31}\right) u_{1}^{\prime}+\left(R_{13} R_{21}-R_{11} R_{23}\right) u_{3}^{\prime}}{R_{11} R_{33}-R_{31}^{2}}\right]\right\} .
$$

We apply this equation to reconstruct $\mathrm{NO}_{2}$ process taking into account its covariance relations with $\mathrm{NH}_{4}$ and $\mathrm{NO}_{3}$ processes.

The equation (16) is presented in finite differences, based on the relation (8):

$$
u_{2}^{k+1}=2 u_{2}^{k}\left\{1-\frac{1}{2 C_{2}}\left[u_{2}^{k}-\frac{\left(R_{21}^{k} R_{33}^{k}-R_{23}^{k} R_{31}^{k}\right) u_{1}^{\prime k}+\left(R_{13}^{k} R_{21}^{k}-R_{11}^{k} R_{23}^{k}\right) u_{3}^{\prime k}}{R_{11}^{k} R_{33}^{k}-\left(R_{31}^{k}\right)^{2}}\right]\right\} \text {. }
$$

The results of computational experiments performed using the equation (17) are summarized in Fig. 4.

Point out that the variable effect coefficients were applied in equation (17) due to the fact that the covariance matrix $R_{i j}$ elements were calculated using the samples from the series of observations at different intervals of moving averaging of $u_{i} u_{j}$ products. 

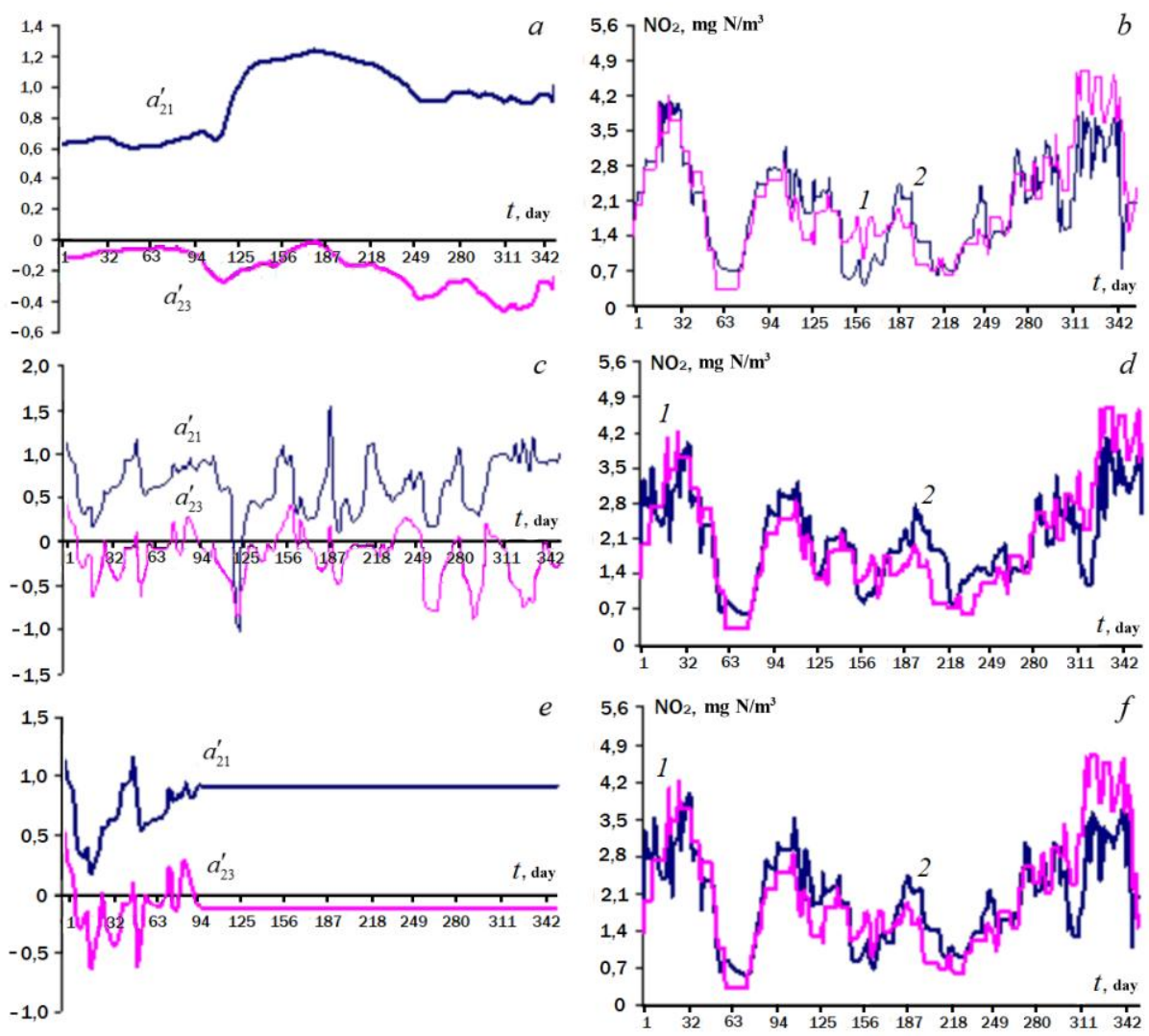

F i g. 4. Effect coefficients in the dynamic-stochastic equation (17) and comparison of the observed (curves 1) and the modeled by (17) (curves 2) concentrations of $\mathrm{NO}_{2}$

In Fig. 4, $a$ the scenarios of dimensionless factors $a_{21}^{\prime}$ and $a_{23}^{\prime}$, determined by solving equations (15) in which the elements of the covariance matrix were calculated by performing the moving averaging of more than 200 values of observation time series, are given. The results of the reconstruction of $\mathrm{NO}_{2}$ observation time series with these factors taken into account are shown in Fig. 4, $b$ (curve 1 ). In order to assess the accuracy of $\mathrm{NO}_{2}$ process reconstruction, the ratio of the error variance of time series reconstruction to the variance of the series itself was found. This ratio is 0.067 , which corresponds to a ratio of mean-square values of 0.26 .

Shorter sections of observation series when calculating the current values of the covariance matrix reduced the accuracy of $\mathrm{NO}_{2}$ process reconstruction. Examples of applying a matrix with elements calculated from 25 values of the observation series are shown in Fig. $4, c, d$. In this case, the scenarios of factors $a_{21}^{\prime}$ and $a_{23}^{\prime}$ became more variable (Fig. $4, c$ ), however, the accuracy of $\mathrm{NO}_{2}$ process reconstruction with regard to the variances decreased to 0.69 , and with regard to $\mathrm{NO}_{2}$ mean-square values - to 0.83 .

Another experiment was carried out for the case when the researcher has a short series of observations of the process under reconstruction to estimate the covariance matrix. To obtain the estimates, the first 100 values of $\mathrm{NO}_{2}$ 
observation series were selected. From the $101^{\text {st }}$ value and up to the end of this series the values were reconstructed taking into account the covariance matrix recorded at the $100^{\text {th }}$ calculation step. Graphs of the effect coefficients are given in Fig. 4, $e$, and the results of series reconstruction - in Fig. 4, $f$. The accuracy of $\mathrm{NO}_{2}$ process reconstruction with regard to variances ratio was 0.37 , and with regard to root-mean-square values -0.61 .

Conclusion. The methods of modeling processes in marine ecosystems considered in this paper are based on the principles of adaptive balance of causes and informational unity of dynamic models of processes and observational data on them. Adaptive balance principle allows one to construct the $1^{\text {st }}$ and the $2^{\text {nd }}$ order models, which provide automatic adjustment of marine ecosystem model variables to each other, while preserving the material balances of substance transformation reactions in the marine environment. As it was shown by the results of computational experiments, the $2^{\text {nd }}$ order adaptive models have higher sensitivity to external effects on the ecosystem and a higher rate of adaptation to them. The principle of informational unity of the model and observational data provides the assimilation of new information in adaptive models of ecosystems by including observational data as additional sources of external effects.

The principles of marine ecosystems adaptive modeling are illustrated on the materials of hydrochemical observations performed in the Sevastopol Bay. A comparative analysis of two methods for reconstruction of nitrite concentration dynamics over time series of ammonium and nitrate observations was carried out. In the first method it was assumed that only mean values of these processes are known. This fact was used to estimate the effect coefficients by the method of normalized ratios of average values in the nitrite concentration $2^{\text {nd }}$ order adaptive equation. In the second method statistical relations between the processes were considered known, which made it possible to apply an adaptive dynamic-stochastic nitrite concentration equation with effect coefficients calculated using the covariance matrix of three processes. The analysis results showed that the dynamic-stochastic equation provides significantly higher accuracy of reconstruction of nitrite concentration unobservable process in comparison with the method of normalized ratios of average values. In addition, the reconstruction accuracy rises with an increase in the length of the time series of observations applied when constructing their covariance matrix.

\section{REFERENCES}

1. Von Bertalanffy, L., 1972. The History and Status of General Systems Theory. The Academy of Management Journal, [e-journal] 15(4), pp. 407-426. https://doi.org/10.5465/255139

2. Moiseev, N.N., Aleksandrov, V.V. and Tarko, A.M., 1985. Chelovek i Biosfera: Opyt Sistemnogo Analiza i Ehksperimenty s Modelyami [The Man and the Biosphere. Experience of System Analysis and Experiments with Models]. Moscow: Nauka, 271 p. (in Russian).

3. Long, R.D., Charles, A. and Stephenson, R.L., 2015. Key Principles of Marine Ecosystem-Based Management. Marine Policy, [e-journal] 57, pp. 53-60. http://dx.doi.org/10.1016/j.marpol.2015.01.013

4. Timchenko, I.E., Igumnova, E.M. and Timchenko, I.I., 2000. Sistemnyy Menedzhment $i$ ABCTekhnologii Ustoychivogo Razvitiya [System Management and ABC-Technologies of Sustainable Development]. Sevastopol: ECOSI-Gidrofizika, 225 p. (in Russian).

5. Costanza, R., Groot, R. de, Sutton, P., Ploeg, S. van der, Anderson, S.J., Kubiszewski, I., Farber, S. and Turner, R.K., 2014. Changes in the Global Value of Ecosystem Services. PHYSICAL OCEANOGRAPHY VOL. 26 ISS. 1 (2019) 
Global Environmental Change, [e-journal] 26, pp. 152-158. http://dx.doi.org/10.1016/j.gloenvcha.2014.04.002

6. Kalman, R.E., 1960. A New Approach to Linear Filtering and Prediction Problems. Journal of Basic Engineering, [e-journal] 82(1), pp. 35-45. http://dx.doi.org/10.1115/1.3662552

7. Holling, C.S., ed., 1978. Adaptive Environmental Assessment and Management. Wiley IIASA. Chichester: John Wiley, 377 p. Available at: http://pure.iiasa.ac.at/id/eprint/823/1/XB78-103.pdf [Accessed: 30 December 2018].

8. Timchenko, I.E., 1984. Stochastic Modeling of Ocean Dynamics. Chur: Harwood Academic Publishers, $320 \mathrm{p}$.

9. Holland, J.H., 1992. Adaptation in Natural and Artificial Systems: an Introductory Analysis with Applications to Biology, Control, and Artificial Intelligence. Cambridge, Mass.: MIT Press, 211 p.

10. Timchenko, I.E. and Igumnova, E.M., 2005. Integrated Management of Economic-Ecological SeaLand Systems. Physical Oceanography, [e-journal] 15(4), pp. 247-263. https://doi.org/10.1007/s11110-005-0046-X

11. Ivanov, V.A., Igumnova, E.M. and Timchenko, I.E., 2012. Coastal Zone Resources Management. Kiev: Academperiodika, 304 p.

12. Timchenko, I.E., Igumnova, E.M. and Timchenko, I.I., 2016. Adaptive Balance Models for Environmental-Economic Systems. CreateSpace Independent Publishing Platform, 486 p.

13. Platt, T., Mann, K.H. and Ulanowicz, R.E., eds., 1981. Mathematical Models in Biological Oceanography. Paris: The UNESCO Press, 157 p.

14. Murray, J.D., 2008. Mathematical Biology II: Spatial Models and Biomedical Applications. New-York: Springer, 736 p.

15. Fasham, M.J.R., Ducklow, H.W. and McKelvie, S.M., 1990. A Nitrogen-Based Model of Plankton Dynamics in the Oceanic Mixed Layer. Journal of Marine Research, [e-journal] 48(3), pp. 591-639. https://doi.org/10.1357/002224090784984678

16. Forrester, J.W., 1991. System Dynamics and the Lessons of 35 Years. In: K. B. De Greene, ed., 1991. The Systemic Basis of Policy Making in the 1990s. Massachusetts: Sloan School of Management MIT, 35 p. Available at: http://static.clexchange.org/ftp/documents/systemdynamics/SD1991-04SDandLessonsof35Years.pdf [Accessed: 30 December 2018].

17. Saaty, T.L., 2000. Fundamentals of Decision Making and Priority Theory with the Analytic Hierarchy Process. Pittsburgh: RWS Publications, 478 p.

18. Svishchev, S.V., 2018. Adaptive Modeling of Nitrification in the Sevastopol Bay. Ekologicheskaya Bezopasnost' Pribrezhnoy $i$ Shel'fovoy Zon Morya = Ecological Safety of Coastal and Shelf Zones of Sea, (2), pp. 60-65. doi:10.22449/2413-5577-2018-2-60-65

About the authors:

Igor E. Timchenko - Head of System Analysis Department, FSBSI MHI (2 Kapitanskaya Str., Sevastopol, 299011, Russian Federation), Dr. Sci. (Phys.-Math.), Professor, ResearcherID: A-86502017, timchenko.syst.analysis@mhi-ras.ru

Ekaterina M. Igumnova - Leading Engineer, Marine Optics and Biophysics Department, FSBSI MHI (2 Kapitanskaya Str., Sevastopol, 299011, Russian Federation)

Sergey V. Svishchev - Leading Engineer-Researcher, System Analysis Department, FSBSI MHI (2 Kapitanskaya Str., Sevastopol, 299011, Russian Federation), ResearcherID: T-1962-2018, ORCID ID: 0000-0003-4673-7609, sergsvishchev09@gmail.com

Contribution of the co-authors:

Igor E. Timchenko - the idea of the adaptive balance of causes method and the derivation of equations of marine ecosystem adaptive model

Ekaterina M. Igumnova - carrying out the calculations on the model and the analysis of simulation results

Sergey V. Svishchev - discussion of the method and its application to the materials of hydrochemical observations

All the authors have read and approved the final manuscript.

The authors declare that they have no conflict of interest. 